\title{
Alimentação do Bebê nos Dois Primeiros Anos de Vida: o Papel do Cirurgião-Dentista Enquanto Agente de Promoção de Saúde
} Baby's Nourishment in the First Two Years of Life: Dentist's Role as a Health Promoter Agent

Fabiana Bucholdz Teixeira Alves ${ }^{1}$, Ana Claudia Rodrigues Chibinski ${ }^{2}$, Jenny Abanto ${ }^{3}$, Daniela Prócida Raggio ${ }^{4}$

\begin{abstract}
Health professionals have an important role in assisting parents or guardians about children nutrition and the development of proper habits to achieve and maintain good health. The objective of this study was to provide relevant information about proper eating habits for children aging 0 to 2 years old. This paper, aiming pediatric dentists but interesting for all health professionals, sequences the most appropriate moment for introducing foods on the child's diet, from exclusive breastfeeding to the introduction of all food groups, by the age of two. These informations should be able to help dentists in contributing for the adoption of proper eating habits in order to children achieve normal development of stomatognathic system as well as maintain systemic health.
\end{abstract}

Key words: infant nutrition; oral health; supplementary feeding; weaning ; breastfeeding

\section{Resumo}

Os profissionais de saúde têm um papel importante na orientação de pais ou responsáveis sobre nutrição infantil e no desenvolvimento de hábitos condizentes com a condição de saúde atual e futura. $O$ objetivo deste trabalho foi apresentar, por meio de uma revisão da literatura, as informações necessárias para o aconselhamento de hábitos alimentares para crianças na faixa etária de 0 a 2 anos de idade. Direcionado a odontopediatras, mas de interesse para todos os profissionais da saúde, este artigo sequencia a época mais adequada para a introdução dos alimentos, desde o aleitamento materno exclusivo até a alimentação completa da criança de dois anos, com vistas à adoção de hábitos alimentares adequados ao correto desenvolvimento do sistema estomatognático e a manutenção da saúde como um todo.

Palavras-chave: nutrição do lactente; saúde bucal; suplementação alimentar; desmame; aleitamento materno
${ }^{1}$ Doutora em Odontopediatria na Faculdade de Odontologia da Universidade de São Paulo/FOUSP - São Paulo/SP, Brasil - e-mail: fabi.teixeira@usp.br

${ }^{2}$ Professora Assistente de Odontopediatria da Universidade Estadual de Ponta Grossa, Ponta Grossa/PR - e-mail: anachibinski@hotmail.com

${ }^{3}$ Aluna de Doutorado em Odontopediatria na Faculdade de Odontologia da Universidade de São Paulo/FOUSP - São Paulo/SP, Brasil - e-mail: jennyaa@usp.br

${ }^{4}$ Professora Doutora do Departamento de Ortodontia e Odontopediatria da Faculdade de Odontologia da Universidade de São Paulo; Doutora pela FOUSP São Paulo/SP, Brasil - e-mail: danielar@usp.br

Correspondência: Ana Cláudia Rodrigues Chibinski

Endereço: Departamento de Odontologia - Universidade Estadual de Ponta Grossa Avenida Carlos Cavalcanti, 4748, CEP 84030-900 - Uvaranas, Ponta Grossa, PR Brazil

Fone: (42) 32203741

E-mail: anachibinski@hotmail.com

Data de Submissão: 19/07/2010

Data de Aceite: 07/11/2011

\section{Introdução}

A educação alimentar e a formação dos hábitos alimentares iniciam-se muito precocemente. Acredita-se que a base dessa formação se dê no primeiro ano de vida, quando inicia o contato da criança com os diferentes tipos de alimentos. Uma vez que este contato se dá no seio familiar, sofre forte influência dos hábitos familiares e de fatores sócio-econômico-culturais. Portanto a preocupação com a educação alimentar deve existir desde o nascimento da criança e deve ser encarada como uma medida de promoção de saúde, pois hábitos alimentares aprendidos na infância dificilmente serão modificados posteriormente. (ROCHA et al., 1998; VELASCO et al., 1993). Portanto, a instituição de uma dieta adequada para as crianças desde o primeiro ano de vida pode prevenir o desenvolvimento de problemas tanto de saúde bucal quanto sistêmica, sendo os mais conhecidos a cárie dental e a obesidade.

É possível observar mudanças nos hábitos alimentares das populações devido ao crescimento das indústrias. Alimentos ricos em fibras e nutrientes (frutos, legumes e verduras) foram e estão sendo trocados por alimentos industrializados, ricos em gorduras e carboidratos refinados (açúcares e farinhas).

Do ponto de vista odontológico, este padrão alimentar, constituído por alimentos facilmente fermentáveis, estimulam a proliferação de microorganismos e contribuem para a formação de um biofilme dental mais patogênico. A freqüência com que os alimentos são ingeridos, bem como a sua consistência também contribuem para o aumento do risco de lesões cariosas. O fato dos alimentos pastosos exigirem menos esforço mastigatório que os alimentos crus e fibrosos, leva a uma redução na salivação, comprometendo o principal mecanismo natural de limpeza da boca (clearance salivar). (BIRCH et al., 1990). Por outro lado, alguns alimentos apresentam propriedades que podem oferecer certa proteção contra a cárie, como o queijo, presunto, ovo, pipoca, as sementes aleaginosas (nozes, avelã, castanha de caju) e as 
gorduras, elementos nocivos quando consumidos em excesso, são capazes de contribuir para a redução da cariogenicidade dos alimentos. (MATEOS, 1999). Portanto, os hábitos alimentares se constituem num componente importante a ser controlado quando se pretende estabelecer um equilíbrio na cavidade bucal.

Como os hábitos alimentares estão relacionados com o desenvolvimento da lesão cariosa e sabendo-se que a boca é o único órgão que tem contato direto com o alimento, é inaceitável que os profissionais não conversem com seus pacientes sobre dieta e nutrição. (ALMEIDA, 1999). Orientar sobre hábitos alimentares adequados, destacando o aleitamento materno, é um grande desafio para o profissional de saúde, uma vez que ele se depara com uma demanda para a qual não foi preparado, e que exige sensibilidade e habilidade no seu trato. (ARAÚJO; ALMEIDA, 2007).

A American Academy of Pediatric Dentistry (2007/2008) incentiva odontopediatras e outros profissionais de saúde que tratam diretamente de crianças a proporcionarem aconselhamento nutricional, compatível com a sua formação e experiência, em articulação com ações preventivas para os seus pacientes.

Portanto, o objetivo deste estudo é apresentar, por meio de uma revisão da literatura, um protocolo para aconselhamento de hábitos alimentares, voltado para crianças na faixa etária de 0 a 2 anos de idade, seqüenciando a época mais adequada para a introdução dos alimentos, desde o aleitamento materno exclusivo até a alimentação completa da criança de dois anos.

\section{Aleitamento Materno Exclusivo}

O aleitamento materno é a melhor maneira de proporcionar o alimento ideal para o crescimento saudável e o desenvolvimento dos recém-nascidos. A Wolrd Health Organization (2001) recomenda, para a população em geral, que os bebês recebam exclusivamente leite materno durante os primeiros seis meses de idade. Para fazer com que as mães consigam amamentar exclusivamente, até os seis meses, a Wolrd Health Organization (WHO) e o Fundo das Nações Unidas para a Infância (Unicef) recomendam ainda: iniciar a amamentação nas primeiras horas de vida da criança; amamentação exclusiva, ou seja, o lactante recebe apenas leite materno, sem nenhum outro alimento ou líquido, nem mesmo água; amamentação sob livre demanda, ou seja, todas as vezes que a criança quiser, dia e noite; não usar mamadeiras nem chupetas. (WORLD HEALTH ORGANIZATION; UNICEF, 1998).

É um componente de vital importância para a saúde e nutrição na fase inicial da vida. Quanto mais a criança mamar no peito, mais protegida estará. (HABICHT; DA VANZO; BUTZ, 1986; VICTORA et al., 1987). Somente no final da década de 80 ficou claro que a amamentação exclusiva nos primeiros meses de vida é mais segura do que outros tipos de alimentação da criança. O efeito protetor do leite materno contra diarréias e doenças respiratórias pode diminuir substancialmente quando a criança recebe, além do leite materno, qualquer outro alimento, incluindo água ou chás. Isso se deve ao fato de que a criança não amamentada exclusivamente recebe menos fatores de proteção existentes no leite materno, além da possibilidade de receber alimentos ou água contaminados.(GIUGLIANI; VICTORA, 2000).

As vantagens da amamentação materna sobre a alimentação artificial do bebê podem ser vistas sob quatro óticas principais: 1) aspecto emocional do bebê e da mãe; 2) aspecto nutricional do leite; 3) aspecto imunológico; 4) aspecto morfofuncional.

O leite materno propicia nutrição de alta qualidade para a criança e contém todos os nutrientes de que a criança precisa nos primeiros seis meses de vida: água em quantidade suficiente (mesmo em clima quente e seco o bebê que apenas recebe aleitamento materno não precisa nem mesmo de água); proteínas e gorduras adequadas para a criança e na quantidade certa; quantidade superior de lactose se comparado aos outros leites; vitaminas, sais, cálcio e fósforo em quantidades suficientes. Não há grande quantidade de ferro, mas ele é bem absorvido no intestino da criança. A presença de uma enzima, denominada lipase, favorece a digestão de gorduras e facilita a absorção do leite materno, que não é "pesado" como os outros leites. Além desses nutrientes, o leite materno possui componentes imunológicos, sendo os principais: IgA secretora, lactoferrina, lisozima, macrófagos e fator bífido (JUNQUEIRA, 2000).

Sabe-se que a amamentação natural previne infecções, é completa em termos de nutrientes, melhora a relação mãe-filho, auxilia no desenvolvimento do sistema estomatognático da criança, sendo tudo que o bebê precisa nos primeiros seis meses de vida. Além de vir sempre na temperatura ideal, dispensar preparo e mamadeira, não custa nada e é um direito da mãe e da criança.

Para Giugliani (2000), uma boa atuação do dentista para promover, proteger e apoiar a amamentação requer não apenas conhecimentos sobre aleitamento materno, mas também habilidade clínica de aconselhamento. O aconselhamento deve substituir a consulta. O profissional não deve julgar as atitudes das mães, mas sim oferecer espaço e estímulo para que elas possam se expressar. É necessário dedicar tempo e interesse, por meio de uma escuta ativa facilitada pela comunicação não verbal. Torna-se importante conquistar a confiança das mães e compreender seus sentimentos. A cada encontro, o profissional deve, aos poucos, acrescentar novas informações de acordo com a prioridade do momento, em linguagem acessível e simples. Elogios e reconhecimento são importantes para aumentar a confiança da mãe e encorajá-la a modificar comportamento e manter práticas saudáveis.

Em relação ao sistema estomatognático, quando o bebê é amamentado de forma natural, estimula-se o desenvolvimento neurooclusal. Ao sugar o peito da mãe, o bebê respira pelo nariz; o ato de morder, avançar e retrair a mandíbula faz com que todo sistema muscular, principalmente masseteres, temporais, e pterigóideos, vão se desenvolvendo e adquirindo o tônus muscular necessário para receber a primeira dentição e realizar a abrasão fisiológica; os movimentos protrusivo e retrusivo exercitam, ao mesmo tempo, as partes posteriores dos discos articulares e superiores das ATMs, e como resposta, há o crescimento ântero-posterior dos ramos mandibulares e, simultaneamente, a modelação do ângulo mandibular (PLANAS,1988). Desta forma, o aleitamento materno está intimamente relacionado ao estabelecimento da fonação, da deglutição, da respiração correta, além de promover o crescimento harmônico de todo o sistema estomatognático. (MOREIRA; CHAVES; NÓBREGA, 2004). Com os estímulos da amamentação, mastigação e respiração, estimula-se o desenvolvimento normal crânio-facial do bebê, corrigindo a desproporção crânio cefálico/crânio facial, sintomatologia de distoclusão e diminuição da altura da face observadas no neonato. (MEDEIROS; RODRIGUES, 2001).

Existem relatos na literatura científica que a criança amamentada ao seio não usa mamadeiras e chupetas, que são causadoras de estímulos mal direcionados de crescimento. Vários autores demonstram a existência da forte correlação entre o período de aleitamento materno e o aparecimento de hábitos bucais (JUNQUEIRA, 2000; ROBLES et al., 1999; SERRA-NEGRA; PORDEUS; ROCHA, 1997; SOUSA et al., 2004; BARROS; ELIAS, 2001).

A WHO (2000a) recomenda que o aleitamento materno tenha continuidade até o segundo ano de vida, pois continua sendo uma importante fonte de nutrientes além de continuar conferindo proteção contra doenças infecciosas. Mas apesar das inúmeras vantagens da amamentação para a criança, a mãe, a família e a sociedade em geral, ele não deve ser oferecido como fonte única de alimentação a partir do sexto mês, quando há necessidade de 
complementação com outros tipos de alimentos para o desenvolvimento global da criança.

\section{Aleitamento Materno Complementado}

O espaço de tempo que vai desde a introdução do novo alimento até a suspensão completa do leite materno é o período denominado aleitamento materno complementado. Neste período, ocorre a introdução na dieta de outros alimentos, associados ao leite materno. Trata-se da alimentação complementar, e compreende qualquer alimento nutritivo, sólido ou líquido, diferente do leite humano, oferecido à criança amamentada. (WORLD HEALTH ORGANIZATION; UNICEF, 1998).

É erroneamente conhecido como "período de desmame", termo que deve ser evitado, pois pode dar a falsa impressão de que é um período onde são usados alimentos para provocar o desmame e não para complementar o leite materno. (GIUGLIANI, 2000; PIWOZ; HUFFMAN; QUINN, 2003).

A WHO (2001) recomenda que depois dos seis meses, com o objetivo de suprir suas necessidades nutricionais, a criança deve começar a receber alimentação complementar segura e nutricionalmente adequada, juntamente com a amamentação, até os dois anos de idade. É apenas a partir dos 6 meses de idade que as necessidades nutricionais do lactente não podem ser supridas apenas pelo leite humano. Também é a partir dessa idade que a maioria das crianças atinge um estágio de desenvolvimento geral e neurológico (mastigação, deglutição, digestão e excreção) que a habilita a receber outros alimentos. Vale ressaltar que receber os alimentos complementares tardiamente também é desfavorável, porque o crescimento da criança estaciona ou fica lento, e o risco de desnutrição e de deficiência de micronutrientes aumenta. (CARVALHO, 1997; WOLRD HEALTH ORGANIZATION, 2000b).

É importante lembrar que um dos fatores de risco para a ocorrência de anemia é a introdução tardia dos alimentos complementares. É comum o desenvolvimento da anemia ferropriva em crianças com dieta essencialmente a base de leite de vaca após o sexto mês de vida, época em que há crescimento rápido e aumento da necessidade de ferro. O suplemento de primeira escolha é o sulfato ferroso, devido à sua distribuição gratuita nos postos de saúde. Deve-se reavaliar a fórmula escolhida em função da tolerância do paciente e do custo do medicamento. (LACERDA et al., 2006).

Para a criança crescer saudável, ela deve receber alimentos complementares adequados no momento oportuno. Uma alimentação adequada deve ser rica em energia, proteínas e micronutrientes (particularmente ferro, zinco, cálcio, vitaminas A e C e fosfatos), isenta de contaminação (sem germes patogênicos, toxinas ou produtos químicos prejudiciais), não muito salgada ou condimentada, fácil de ser consumida pela criança (apresentação adequada para a idade), em quantidade apropriada e que seja disponível e acessível. É de fundamental importância que a criança goste da dieta e que ela seja culturalmente aceita. (WORLD HEALTH ORGANIZATION, 2000a, 2000b).

Os alimento complementares devem ser introduzidos gradativamente. Deve-se apresentar para a criança um alimento de cada vez, com intervalo de três a sete dias. Este cuidado permite a observação de qualquer reação adversa por parte da criança. Devem ser oferecidos à criança empregando-se colher e copo, cujo uso estimula o desenvolvimento e crescimento das estruturas faciais. (CARVALHO, 1997). É fundamental comentar que a introdução dos alimentos complementares não deve, em hipótese alguma, alterar a freqüência das mamadas ao seio materno. (BIRCH, 1997).

Crianças de seis a vinte e quatro meses apresentam certa resistência ao consumo de alimentos ricos em ferro, como carnes, peixe, fígado, sendo necessárias estratégias para elevar a ingestão do ferro, como o enriquecimento de alimentos infantis e suplementação com ferro medicamentoso, além do consumo de alimentos ricos em vitamina C (laranja, goiaba, folhas verdes, couveflor, pimentão, limão, manga, mamão, banana, maracujá, pêssego, tomate). (GIUGLIANI, 2000).

As crianças tendem a preferir alimentos com alta densidade energética ${ }^{5}$. Porém, o consumo exagerado desses alimentos pode saciar rapidamente a criança, o que acaba por impedir a ingestão de alimentos variados. Deve-se tentar reduzir a quantidade de sacarose da alimentação do bebê, evitando-se bolachas, salgadinhos, e refrigerantes, porque tendem a reduzir o apetite. Segundo o Comitê sobre os Aspectos Médicos de Políticas Alimentares (COMA), é recomendado que o consumo de produtos não láticos, sacarose e xaropes de glicose, sejam reduzidos e substituídos por frutas e vegetais; a ingestão de doces não deve ser maior que quatro vezes ao dia, devendo ser consumido logo após as refeições principais. Os alimentos industrializados, ricos em gordura, e carboidratos refinados, os quais fermentam e facilitam a proliferação bacteriana na boca, possuem reflexos negativos sobre a cavidade bucal, sendo aconselhável a sua substituição por alimentos ricos em fibras e nutrientes, como frutas, verduras e legumes. Além de que esses últimos requerem maior esforço mastigatório do que os alimentos pastosos, que grudam nos dentes e reduzem a salivação, aumentando o risco de cárie. (MATEOS,1999; ROSENBLATT, 1998).

Outros fatores importantes a serem destacados é que a criança deve ser estimulada a comer no horário certo das refeições principais, bem como, paulatinamente, a alimentar-se sozinha, sob supervisão. Em momento algum a criança deve ser forçada a comer ou chantageada para se alimentar quando não está com fome. Outras medidas importantes são apresentadas no Quadro 1.

A incorporação dos alimentos complementares na alimentação diária da criança traz consigo a necessidade de adoção das melhores práticas possíveis para manipulação dos alimentos. Entre as principais regras a serem observadas, destaca-se a necessidade de lavagem das mãos com sabonete antes de manusear os alimentos; ingestão de alimentos frescos; usar utensílios limpos; lavar os alimentos de forma adequada; armazenar alimentos perecíveis na geladeira e não em temperatura ambiente; consumir os alimentos até duas horas após o seu preparo, na ausência de geladeira; cozinhar os alimentos de forma adequada e proteger os alimentos e utensílios contra animais (baratas, moscas, ratos) e poeira (GIUGLIANI; VICTORA, 2000; GIUGLIANI, 2000). 
Quadro 1 - Dez passos da alimentação saudável para crianças com menos de 2 anos de idade

Passo 1: Fornecer somente leite materno até os seis meses de idade, sem oferecer água, chás, ou quaisquer outros alimentos.

Passo 2: A partir dos seis meses de idade, introduzir de forma lenta e gradual outros alimentos a dieta da criança, mantendo o aleitamento natural até os dois anos de idade.

Passo 3: A partir dos seis meses, dar alimentos complementares (cereais, tubérculos, carnes, leguminosas, frutas e legumes) três vezes ao dia, se a criança receber leite materno, e cinco vezes ao dia, se estiver desmamada.

Passo 4: A alimentação complementar deve ser oferecida sem rigidez de horários, respeitando-se sempre a vontade da criança.

Passo 5: A alimentação complementar deve ser espessa desde o inicio e oferecida de colher; começar com consistência pastosa (papas e purê) e gradativamente, aumentar a sua consistência até chegar a alimentação da família.

Passo 6: Oferecer a criança diferentes alimentos ao dia. Uma alimentação variada é uma alimentação colorida.

Passo 7: Estimular o consumo diário de frutas, verduras e legumes nas refeições.

Passo 8: Evitar açúcar, café, enlatados, frituras, refrigerantes, balas, salgadinhos, e outras guloseimas, nos primeiros anos de vida. Usar sal com moderação.

Passo 9: Cuidar da higiene no preparo e manuseio dos alimentos; garantir o seu armazenamento e conservação adequados.

Passo 10: Estimular a criança doente e convalescente a se alimentar, oferecendo sua alimentação habitual e seus alimentos preferidos, respeitando a sua aceitação.

Fonte: Brasil/Ministério da Saúde/Organização Pan-Americana da Saúde. Guia alimentar para crianças menores de 2 anos. Serie A. Normas e manuais técnicos $n^{\circ} 107$. Brasília, DF, Ministério da Saúde; 2002.

\section{Cardápios}

As necessidades nutricionais de cada indivíduo diferem, devido a sua constituição genética, características morfológicas e fisiológicas, bem como atividade e eficácia metabólica. Os elementos fundamentais à nutrição - proteínas, lipídios, carboidratos, vitaminas, sais minerais e água - devem guardar adequada proporção entre si para que haja perfeita utilização pelos órgãos e tecidos. (PALMA, 2004).

Segundo a WHO (2000a), deve-se aumentar gradualmente a consistência e a variedade dos alimentos à medida que a criança cresce, adaptando a dieta às necessidades e habilidades da criança. Quanto ao número de refeições diárias consumidas por crianças menores de dois anos, há poucos estudos no Brasil.

As estimativas da densidade energética (o número de calorias por unidade de volume ou peso do alimento), fornecida pelos alimentos complementares têm sido feitas em bases teóricas e sofrem limitações devido as peculiaridades metodológicas dos estudos que envolvem crianças menores de 2 anos. (MONTE; GIUGLIANI, 2004). Portanto, a densidade energética dos alimentos complementares recomendada varia de acordo com a idade da criança, a quantidade de ingestão de leite materno, concentração de gordura no leite materno e freqüência com que a criança recebe os alimentos complementares. (BRASIL, 2002).

Estima-se que, em países em desenvolvimento, havendo ingestão regular de leite materno, os alimentos complementares devem suprir aproximadamente $200 \mathrm{kcal}$ por dia dos 6 aos 8 meses de idade, $300 \mathrm{kcal}$ dos 9 aos 11 meses e $550 \mathrm{kcal}$ dos 12 aos 23 meses. (WORLD HEALTH ORGANIZATION, 1995). A WHO (2003) atualmente recomenda, para as crianças amamentadas, duas a três
Quadro 2 - Sugestão de Cardápio, dividido nas faixas etárias de 6 meses a 1 ano e 1 ano a 2 anos.

\begin{tabular}{|l|c|c|}
\hline Refeição & $\begin{array}{c}\text { Sugestão de cardápio } \\
\text { (aproximadamente 350 } \\
\text { Kcal) } \\
\text { 6esjejum }\end{array}$ & $\begin{array}{c}\text { Sugestão de cardápio } \\
\text { (aproximadamente 550 } \\
\text { Kcal) }\end{array}$ \\
\hline 1 a 2 anos
\end{tabular}

Fonte: Brasil/Ministério da Saúde/Organização Pan-Americana da Saúde. Guia alimentar para crianças menores de 2 anos. Serie A. Normas e manuais técnicos $n^{\circ} 107$. Brasília, DF, Ministério da Saúde; 2002.

refeições com alimentos complementares por dia dos 6 aos 8 meses de idade e três a quatro vezes por dia dos 9 aos 24 meses, com lanches nutritivos adicionais entre as refeições (pedacinhos de fruta ou pão, cuscuz, bolo caseiro, macaxeira) uma a duas vezes ao dia a partir dos 12 meses. (PAN AMERICAN HEALTH ORGANIZATION; WOLRD HEALTH ORGANIZATION, 2003). Caso a densidade de energia ou a quantidade de alimentos complementares por refeição for baixa, ou se a criança estiver totalmente desmamada, pode ser necessária maior freqüência de refeições.

Os alimentos devem ter consistência pastosa e consistente, estimulando o aparelho estomatognático do bebê. Portanto, até o primeiro ano de vida da criança, os alimentos devem ser amassados com garfo e não liquidificados. 
Após a introdução de sucos e papinhas, devem ser fornecidos para as crianças vegetais e outros grãos como arroz e feijão, preferencialmente cozidos e não fritos, e sem excessos de condimentos. A partir dos oito meses, a criança pode receber a mesma alimentação que é consumida pela família, porém os alimentos devem ser amassados, desfiados, picados ou cortados em pequenos pedaços (GIUGLIANI, 2000).

Uma sugestão de cardápio é apresentada no Quadro 2, para a faixa etária de 06 meses a 01 ano e 01 ano a 02 anos. Devese salientar que as normas e recomendações para alimentos na infância são de fundamental importância, mas não devem se restringir apenas às necessidades nutricionais da criança. Sendo o alimento, nos primeiros anos de vida, uma das formas de contato com o mundo externo, é prioritário que o desenvolvimento neuromotor e emocional sejam também considerados (PALMA, 2004).

\section{Considerações Finais}

O cirurgião-dentista, enquanto profissional da saúde, não pode se eximir do aconselhamento dietético/nutricional de seus pacientes. Considerando-se a faixa etária abordada ( 0 a 2 anos), este aconselhamento torna-se ainda mais importante, já que é nesta fase que a aquisição dos hábitos alimentares se dá.

As informações disponíveis neste artigo fornecem subsídios para que o profissional torne-se agente de capacitação e motivação dos pais ou responsáveis. Ao acompanhar o crescimento da criança e as sucessivas alterações nos hábitos alimentares inerentes a cada etapa do protocolo alimentar sugerido, haverá espaço para elogiar comportamentos corretos e/ou intervir a tempo caso hábitos inadequados sejam adotados, com vistas à obtenção e manutenção de padrões nutricionais e dietéticos compatíveis com saúde bucal e sistêmica, dentro de uma proposta acessível para adesão do núcleo familiar.

\section{Referências}

ALMEIDA, J.A.G. Amamentação: um híbrido natureza-cultura. Rio de Janeiro: Fiocruz, 1999. 120p.

AMERICAN ACADEMY OF PEDIATRIC DENTISTRY. Policy on dietary recommendations for infants, children e adolescents. Pediatr. Dent., Chicago, v. 29, Suppl. 7, p. 45-46, 2007/2008.

ARAÚJO, R.M.A.; ALMEIDA, J.A.G. Aleitamento materno: o desafio de compreender a vivência. Rev. Nutr., Campinas, v. 20, n. 4, p. 431438, jul./ago. 2007.

BARROS D.R.; ELIAS F. A importância do aleitamento natural na prevenção de alterações miofuncionais e ortodônticas. Rev. Dent. Press Ortodon. Ortoped. Facial, v. 6, n. 5, p. 111-121, set./out. 2001.

BIRCH L.L. et al. Conditioned flavor preferences in young children. Phisyol. Behav., New York, v. 47, no. 3, p. 501-505, Mar. 1990.

BIRCH L.L. Conducta alimentar en los niños: perspectiva de su desarrollo. In: NUTRICIÓN y Alimentación del Niño em los Prim Años de Vida. Washigton: Organizacion Panamerican de la $S 35$ 1997. p.34-48.

BRASIL. Ministério da saúde. Guia alimentar para crianças menores de 2 anos. Brasília, DF, 2002. (Série A. Normas e manuais técnicos, n. 107).
CARVALHO, G.D. Amamentação uma avaliação abrangente II. Rev. Secretaria Saúde, [S.I.], v. 4, n. 28, p. 8-10, set./out. 1997.

GIUGLIANI, E.R.J.; VICTORA, C.G. Alimentação complementar. J. Pediatr., Rio de Janeiro, v. 76, supl. 3, p. 253-262, dez. 2000.

GIUGLIANI, E.R.J. O aleitamento materno na prática clínica. J. Peditr., v. 76, supl. 3, p. 238-252, dez. 2000.

HABICHT, J.P.; DA VANZO, J.; BUTZ, W.P. Does breastfeeding really save lives, or are apparent benefits due to biases? Am. J. Epidemiol., Baltimore, v. 123, no. 2, p. 279-290, Feb.1986.

JUNQUEIRA, P. Amamentação, hábitos orais e mastigação: orientações, cuidados e dicas. 2. ed. Rio de Janeiro: Revinter, 2000. p.1-26.

LACERDA, E.M.A. et al. Práticas de nutrição pediátrica. São Paulo: Atheneu, 2006. 80p.

MATEOS, A. Brasileiros comem cada vez mais e com pior qualidade. Rev. Assoc. Paul. Cir. Dent., São Paulo, v. 53, n. 1, p. 8-19, 1999.

MEDEIROS, E.B.; RODRIGUES, M.J. A importância da amamentação natural para o desenvolvimento do sistema estomatognático do bebê. Rev. Cons. Reg. Odontol. Pernambuco, Recife, v. 4, n .2, p. 79-83, 2001.

MONTE, C.M.G.; GIUGLIANI, E.R.J. Recomendações para alimentação complementar da criança em aleitamento materno. J. Pediatr., Rio de Janeiro, v. 80, n. 5, p. 131-141, 2004.

MOREIRA, P.V.L.; CHAVES, A.M.B.; NÓBREGA, M.S.G. Uma atuação multidisciplinar relacionada à promoção de saúde oral materno-infantil. Pesqui. Bras. Odontoped. Clín. Integr., João Pessoa, v. 4, n. 3, p. 259-264, set./out. 2004.

PALMA, D. Alimentação no primeiro ano de vida. In: LOPEZ, F.A.; BRASIL, A.L.D. Nutrição e dietética em clínica pediátrica. São Paulo: Atheneu, 2004. p. 53-59.

PAN AMERICAN HEALTH ORGANIZATION; WOLRD HEALTH ORGANIZATION. Guiding principles for complementary feeding of the breastfed child. Washington, 2003. Disponível em: <http://www.who.int/nutrition/publications/IYCF_Directors_Guide.pdf>. Acesso em: 13 maio 2011.

PIWOZ, E.G.; HUFFMAN, S.L.; QUINN, V.J. Promotion and advocacy for improved complementary feeding: Can we apply the lessons learned from breastfeeding? Food Nut. Bull., Tokyo, v. 24, no. 1, p. 29-44, Mar. 2003.

PLANAS, P. Reabilitação neuro-oclusal. Rio de Janeiro: Ed. Médica e Científica, 1988. p. 24-32.

DnDLES, F.R.P. et al. A influência do período de amamentação nos 36 os de sucção persistentes e a ocorrência de maloclusões em crianças com dentição decídua completa. Rev. Paul. Odontol., São Paulo, v. 21, n. 3, p. 4-9, maio/jun. 1999.

ROCHA, C.M. et al. Relação dieta/cárie na odontopediatria - uma análise do consumo de sacarose. Arq. Odontol., Belo Horizonte, v. 34, n. 1, p. 25-31, 1998. 


\section{ROSENBLATT, A. Cárie dentária. In: Clínica odontopediatrica: uma abordagem preventiva. Recife: Ed. UPE, 1998. p. 55-97.}

SERRA-NEGRA, J.M.C.; PORDEUS, I.A.; ROCHA, J.R. Estudo da associação entre aleitamento, hábitos bucais e maloclusões. Rev. Odontol. Univ. São Paulo, São Paulo, v. 11, n. 2, p. 79-86, abr./jun. 1997.

SOUSA, F.R.N. et al. O aleitamento materno e sua relação com hábitos deletérios e maloclusão dentária. Pesqui. Bras. Odontoped. Clín. Integr., João Pessoa, v. 4, n. 3, p. 211-216, set./dez. 2004.

VELASCO, L.F.L. et al. Protocolo alimentar do bebê de zero a três anos de idade. Rev. Odontoped., [S.I.], v. 3, n. 2, p. 133-139, 1993.

VICTORA, C.G. et al. Evidence for protection by breast- feeding against infant deaths from infectious diseases in Brazil. Lancet, London, v. 2, no. 3, p. 17-22, Aug. 1987.

WORLD HEALTH ORGANIZATION. Child Health and Development. Evidence for the ten steps to successful breastfeeding. Geneva, 2000a. Disponivel em: <http://whqlibdoc.who.int/publications/2004/9241591544_eng.pdf>. Acesso em: 13 maio 2011.

WORLD HEALTH ORGANIZATION. Department of Nutrition for Health and Development. Complementary feeding. Family foods for breastfed children. Geneva, 2000b. Disponivel em: $<$ http://whqlibdoc.who.int/hq/2000/WHO_NHD_00.1.pdf $>$. Acesso em: 13 maio $2011 b$.

WORLD HEALTH ORGANIZATION. Global strategy for infant and young child feeding. Geneva, 2001. Disponível em: $<$ http://www.euro.who.int/ data/assets/pdf file/0015/120318/E74173. pdf>. Acesso em: 13 maio 2011c.

WORLD HEALTH ORGANIZATION. Working Group on Infant Growth. An evaluation of infant growth: the use and interpretation of anthropometry in infants. Bull. World Health Organ., Geneve, v. 73, p. 165-174, 1995.

WORLD HEALTH ORGANIZATION; UNICEF. Complementary feeding of young children in developing countries: a review of current scientific knowledge. Geneva World Health Organization, $1998 . \quad$ Disponível em: <http://whqlibdoc.who.int/hq/1998/WHO_NUT_98.1.pdf >. Acesso em: 13 maio 2011. 